The Singapore Economic Review, (2017) 1-28

(C) World Scientific Publishing Company

DOI: $10.1142 / S 0217590817500217$

\title{
ESTIMATING MALAYSIA'S OUTPUT GAP: HAVE WE CLOSED THE GAP?
}

\author{
NUR AIN SHAHRIER* \\ Department of Economics and Finance \\ Sunway University Business School, Malaysia \\ nurains@sunway.edu.my \\ CHUAH LAY LIAN \\ World Bank's Development Research Group \\ Sasana Kijang, 50480, Kuala Lumpur, Malaysia \\ llchuah@worldbank.org
}

Published 8 November 2017

\begin{abstract}
The concepts of potential output and output gap are central to the policymakers' analytical work in providing guidance to policy decisions. This paper presents three different estimation approaches for the Malaysian economy, namely, the univariate, multivariate and structural models. While the multivariate and structural models are mainly underpinned by theory and captured the concept of potential output better, most policymakers still maintain a suite of models to preserve diversity. Diversity provides a greater scope for cross-checking the robustness of results. The paper attempts to contribute by first, providing a critical assessment of the different models in estimating potential output and the output gap, and, second, the usefulness of each models in terms of assessing the drivers of future potential output, predicting price trends and identifying sources of inflation in the economy.
\end{abstract}

Keywords: Output gap; multivariate filter; structural VAR; inflation and prices; productivity.

JEL Classification: C54, E31, E52, E58

\section{Introduction}

Potential output is the maximum level of goods and services that an economy can produce when it is most efficient or at its full capacity. The deviation of the actual output (Gross Domestic Product (GDP)) from its potential output is the output gap. Economists and policymakers are concerned about the size of the output gap as it indicates how close the current output is to the economy's long-term potential output. ${ }^{1}$ A positive output gap

\footnotetext{
* Corresponding author.

${ }^{1}$ The European Central Bank (ECB) uses the output gap as a key indicator to measure inflation, growth of potential output as the point of reference for M3 or money growth, and to design short and medium-term fiscal policies (Horn et al., 2007). Benes et al. (2010) also suggest that central bankers should estimate the size of the output gap so that an appropriate degree of monetary easing can be maintained.
} 
usually indicates that the economy is growing above its potential and demand is strong that factories and workers may need to operate above their most efficient capacity (Jahan and Mahmud, 2013). In such circumstances, there will be pressure on wages and prices that may prompt for a tighter monetary policy stance. A negative output gap indicates an economy that is operating below its potential capacity such that it under-utilizes its factor resources, namely, labor and capital machineries. In this case, the level of unemployment will be higher than average unemployment causing excess supply of labor and downward pressure on real wages and prices. Policymakers then need to consider measures to bring the actual output back to its productive potential capacity.

The existing literature on potential output of Malaysia and its usage is relatively limited. The most recent study by Felipe et al. (2015) used multivariate filter with embedded financial cycle variables to show that for Malaysia, credit growth ${ }^{2}$ is the only significant financial variable that has procyclicality relationship with output gap. Anand et al. (2014) adopted multivariate, univariate and production function methods to show a decline in potential growth of ASEAN-5 countries post 1997 and 2008 financial crises. For Malaysia, this was attributed to lack of governance and quality education. Similarly OECD $^{3}$ (2010) had concluded the decline in potential output across Asian countries and suggested the needs for Malaysia to rebalance its economic growth by shifting from external demand to domestic and regional demand. Earlier study by Lee and Khatri (2001) used cubic spline smoothing method to show the closing in output gap in the year of 2000 .

The main objective of this paper is to extent the work on Malaysia's potential output and the output gap by estimating them using three main estimation techniques; univariate, multivariate and structural methodologies. In addition to those methods by Anand et al. (2014) and OECD (2010) studies, this paper includes multivariate Kalman Filter, univariate state space and structural vector autoregression (SVAR). The parameters and the assumptions applied are estimated specifically to suit Malaysia and in aligned with the country's blue print. From these various estimation results, we identify the output gap estimates that contain useful information in explaining inflation. Finally, we extract additional insights about growth and price drivers in the economy. For instance, the CobbDouglas production function (CDPF) allows us to identify the drivers of long term growth, either from capital, labor or technology. The SVAR method can determine the source of inflationary pressure in the economy, either demand-pull or cost-push factors.

The various estimation results are important for policymakers to cross-check with better accuracy on the country's potential output and output gap (Brouwer, 1998; Cheng et al., 2011). In this paper, it is estimated that the output gap in 2014 is marginally positive, $0.5 \%$, and this gap will close by 2017 when both capacity utilization and unemployment rate reached its long term equilibrium. To increase the potential growth in the economy, the results using CDPF method highlights the need to move toward productivity driven growth in support of Anand et al. (2014).

\footnotetext{
${ }^{2}$ The other two insignificant financial variables are interest rate and property prices.

${ }^{3}$ Organization for Economic Co-operation and Development
} 
The remainder of the paper is structured as follows: Section 2 provides an overview of the common estimation techniques for potential output and the output gap. Section 3 discusses the empirical results by using these three different approaches, examines the long-term drivers of the potential output, identify the sources of inflationary pressure in the economy and analyze the usefulness of these different techniques in predicting price trends. Section 4 discusses the policy implications for Malaysia and the paper concludes in Section 5 .

\section{Methodologies}

The existing literature provides little guidance to the ideal approach in measuring potential output and the output gap. Brouwer (1998) and Cheng et al. (2011) conclude that there is no one particular method which is superior to the other in predicting price trends. It is a common practice among policy institutions to adopt a suite of models, and not just a single approach. In doing so, they are leveraging on the strengths of the various estimation techniques. Broadly, the choice of the models, statistical, model-based or structural, largely depends on the objective of the study and to some extent the data which is available. Although the different approaches can produce somewhat robust results, there is still significant uncertainty surrounding potential output and the output gap estimates.

This study adopts seven different models to estimate potential output and the output gap and these models can be classified into three broad categories. First, unvariate filter methods, which include the linear trend, univariate state space and Hodrick-Prescott (HP). These approaches are purely statistical filters that decompose GDP growth into its trend and cycle components. Second, multivariate filter methods, comprising the macro modelbased multivariate filter (MVF) and multivariate Kalman filter. These methodologies involve estimating the long-term growth that is consistent with the non-accelerating inflation rate of unemployment (NAIRU) and a stable inflation. Third, structural methods, including the CDPF and SVAR approaches. The former is premised on explaining potential output from factor inputs of labor, capital and total factor productivity, while the latter breaks down random disturbances into permanent and transitory components.

\subsection{A brief overview of the common estimation techniques}

One of the most common techniques in estimating the potential output is univariate statistical filters, such as, the linear trend, Hodrick-Prescott (HP) and univariate state space filters. ${ }^{4}$ Univariate filters use statistical estimation to extract the trend component to represent potential output. The main appeal of this approach is that it is simple, straightforward, transparent, and can be applied to any country where GDP data exist. Therefore, this technique is widely adopted especially, in cases where, data limitations cause other estimation approaches to be infeasible. However, the univariate technique has several limitations. The estimates are better thought of as "trend" rather than potential output,

\footnotetext{
${ }^{4}$ See Appendix A for a detailed discussion on the univariate filters including the HP filter, the linear trend and univariate state space model.
} 
since the filter does not take into account information on inflation and unemployment. In other words, they are purely statistical estimation without any significant relationship to other key macroeconomic variables that drive potential output. This contributes to greater output gap whenever there is structural break in the data. During crisis period for instance, the significant declined in GDP will cause large output gap as the economy is operating largely below its potential capacity. The univariate techniques will bring forward this impact to the future estimation of the output gap although other macroeconomic variables have already shown sign of recovery. Furthermore, trend component in HP filter will be determined by the selection of the smoothing parameter (lambda) and like many univariate filters, it suffers from "end-of-sample" problem. This means that estimates toward the end of a given sample period is usually subjected to significant revisions.

The most recent multivariate filter that is now widely used was developed by Benes et al. (2010). It is a macroeconomic model that incorporates economic relationships of actual output with potential output, unemployment, headline inflation and capacity utilization in the manufacturing sector. In this sense, the model ensures consistency between the estimates of the output gap and the dynamics in the labor and product market. The model is also flexible in that it allows the estimated potential output growth to vary with new information and at the same time takes into account the long run stable trend in the macroeconomic variables. The disadvantage of the multivariate filter is that, the estimation of the future potential output by construction is expected to converge to an arbitrarily assumed steady-state growth rate. Furthermore, there are much interdependency between economic variables and these estimates are sensitive to the calibrated parameters. Nevertheless, many studies have used this multivariate filters ${ }^{5}$ to estimate potential output and the output gap (Cheng et al., 2011; Anand et al., 2014). Borio et al. (2013) extended this multivariate filter by embedding financial cycle variables such as interest rate, housing price and credit growth.

Another type of multivariate filter is multivariate Kalman filter that considers the interaction between output gap and wage pressures in the labor market. It exploits information in the labor market as a proxy to the demand in the output market. This is suitable for countries with high economic growth driven by supply-side impetus. Konuki (2008) shows how the multivariate Kalman filter explains the historical dynamics of the labor market better and produces a more plausible output gap measures for Slovakia. However, this filter is very sensitive to the specified initial steady state conditions.

Finally, another common estimation approach is the use of structural models. While the univariate and multivariate filters decompose GDP into its trend and cycle, the structural models such as the CDPF and the SVAR try to decompose growth into drivers of growth and shocks, respectively. Specifically, CDFP decomposes the contribution of growth into labor, capital and total factor productivity (TFP). This approach allows for a closer examination of the drivers of potential output since it is based on theoretical foundation and seems reasonable. However, the main limitation is in obtaining reliable capital stock data and the unobservable actual and potential total factor productivity that are usually derived

\footnotetext{
${ }^{5}$ See Appendix B for the detailed description of the multivariate Kalman filter and the model-based MVF.
} 
from the Hodrick-Prescott statistical filter (Bjornland et al., 2005). This means the trended drivers of potential output, i.e., capital stock and TFP will inherit the problems specified in HP filter. The SVAR approach is based on Blanchard and Quah (1989) whereby random disturbances are decomposed into supply shocks and demand shocks. ${ }^{6}$ It is assumed that demand shocks will have short term effect on output while supply shocks will have a long term effect. The advantage of this method is that it imposed relatively very few constraints on the two variables involved and suffers no end point biased problem (Bjornland et al., 2005). However, these few restrictions can produce misleading results if it is not consistent with how economy works. For instance, the assumption that only the demand shocks can affect the output gap is too restrictive.

\section{Empirical Results}

The discussion of the results is divided into four subsections. Section 3.1 discusses and contrasts the estimated output gaps obtained from the three different approaches, namely, the univariate, multivariate and structural models. Section 3.2 assesses the performance of the different models in terms of their ability to predict price trends. Section 3.3 identifies the sources of inflation during the period of crises. Finally, Section 3.4 focuses on the future drivers of potential output.

\subsection{Estimated output gaps using three different approaches}

From Figure 1, the largest negative gaps using linear trend, HP filter and univariate state space registered during the periods of the two major economic shocks, the Asian Financial Crisis (AFC) in 1997/98 and the Global Financial Crisis (GFC) in 2007/08. The negative output gap registered during AFC appears to be larger than during the GFC and the tech

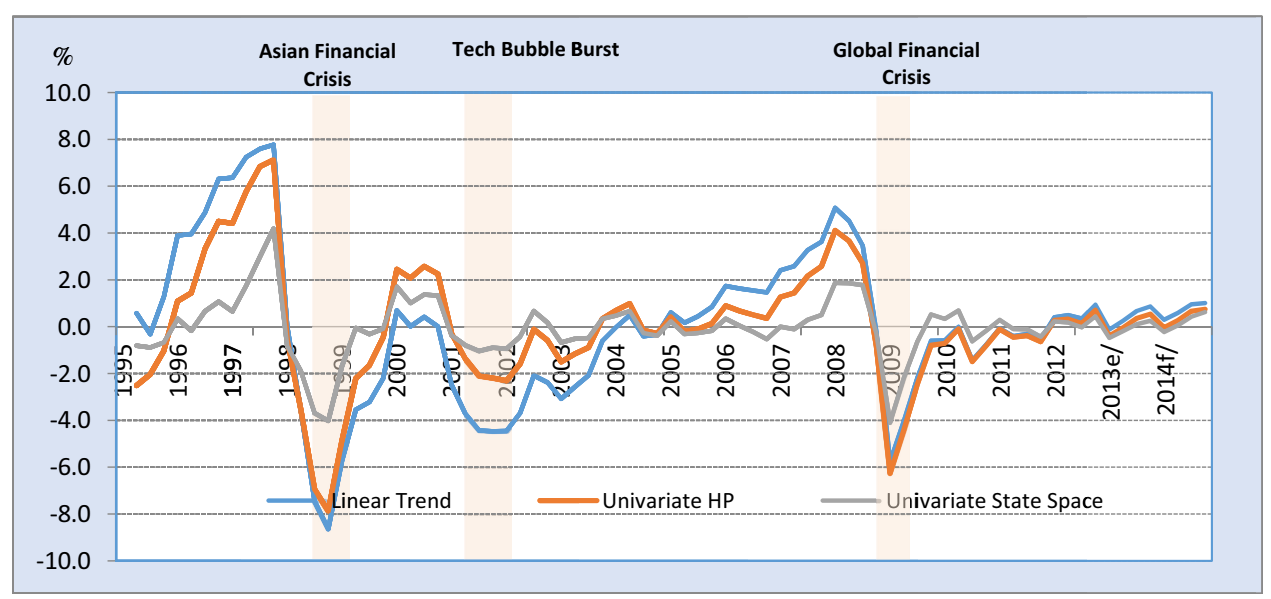

Figure 1. Output Gap Estimates Using Univariate Methods, 1995-2014

${ }^{6}$ Bjornland et al. (2005) and Menashe and Yakhin (2004) adopted the SVAR model to estimate output gaps. 
bubble burst in 2001, suggesting that the effects of shocks from AFC are more severed compared to the other two shocks.

While the quarterly output gap profiles are broadly similar throughout the sample, the size of the output gap differs, as the linear trend estimates showing the largest absolute gap for both economic up-cycles and down-cycles. The larger gap estimates derived from the linear trend approach assume the growth trend to be constant, therefore unable to capture the movements of the business cycle through time. For this reason, the univariate state space model may be a better model, as it appears to have captured the evolution of potential output. As such, it has produced the smallest absolute output gap across all time periods. The size of the output gap estimates derived from the HP filter lies between the output gap estimates produced by linear trend and the univariate state space filter.

Despite producing different magnitudes of output gap estimates, the quarterly time profiles for all the three univariate methods are consistent in picking up important developments in the economy. For example, the large negative output gaps are evident during periods of economic downturns (AFC, Tech Bubble Burst and GFC) and large positive output gaps for periods running up to the major economic shocks.

The multivariate approach which builds on theoretical relationships between the output gap and other macroeconomic variables also produces similar output gap profiles to the univariate models. ${ }^{7}$ The quarterly time profiles for MVKF and the MVF are broadly similar except for periods 2003-2004, where the MVKF produced a small positive output gap and the MVF produced a small negative gap (Figure 2). However, MVKF's results appear to be similar to the univariate state space, while the MVF results are more consistent with the results produced by HP filter and linear trend models. The negative output gap appears to be more plausible as inflation was relatively benign during this period (the average inflation in 2003-2004 is $1.3 \%$; 2005: 3\%).

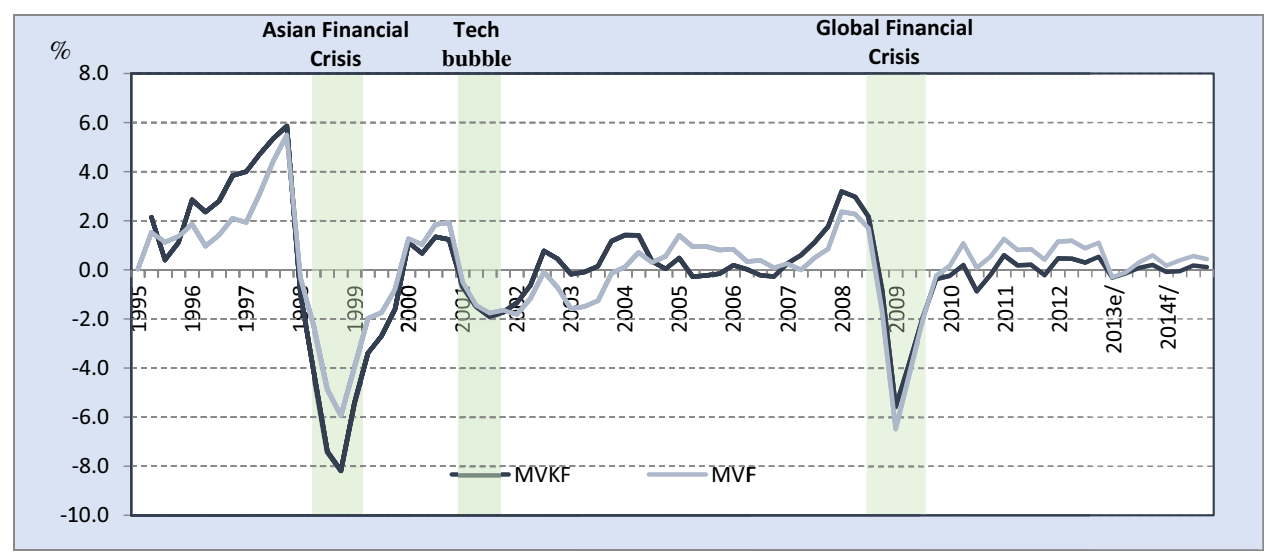

Figure 2. Multivariate Filter Output Gap Estimates, 1995-2014

\footnotetext{
${ }^{7}$ As the multivariate approach explicitly draws on relationships between the output gap and other macroeconomic variables and uses a bigger set of information compared to the univariate methods, Morrow and Roger (2001) found the multivariate Kalman filter to generate smaller output gaps compared to the HP filter for the EU countries.
} 
The divergence in the estimates of the output gap is not uncommon. This is because the models are set up differently, and furthermore literature shows that there is a large degree of uncertainty in estimating output gap. Brouwer (1998) and Cheng et al. (2011) conclude that there is no one particular method which is superior to the other in estimating output gap. Nonetheless, the diversity and increased sophistication of the estimation techniques are useful for policymakers. Various output gap estimates along with many other indicators act as supporting tools, and not the ultimatum in decision making. Different models offer different perspectives on the dynamics of the economy's potential output and, as such a broader spectrum of results allows for policymakers to cross check and debate over the degree of uncertainty of the output gap estimates.

The MVF model, for instance, is built such that it maps the relationships between unemployment, production (capacity utilization) and prices with output gap. In doing so, it provides a consistency check between the output gap estimates with the developments in price trends and, the demand and supply conditions in both the labor and product markets. Based on the results produced by the MVF model, the capacity utilization rate was below its trend during periods of economic crises (AFC and GFC). The negative capacity utilization gaps during these periods suggest weak demand conditions and benign price pressures. The long-term trend of the capacity utilization rate also appears to have shifted down after each major economic shock, slightly above $82 \%$ pre-AFC to between $78 \%$ to $82 \%$ post-AFC (Figure 4 ).

In addition to production conditions, the MVF model also provides information on the labor market conditions. During the AFC, actual unemployment rate increased

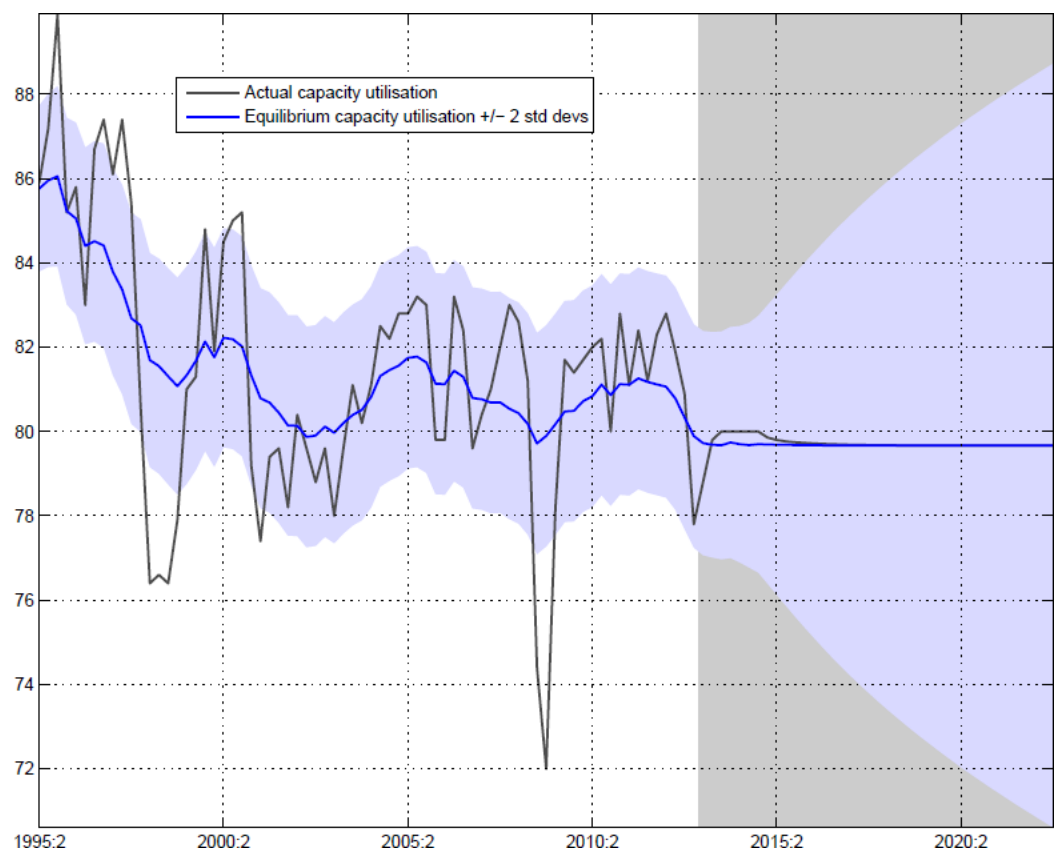

Figure 3. Equilibrium Capacity Utilization (\%) 


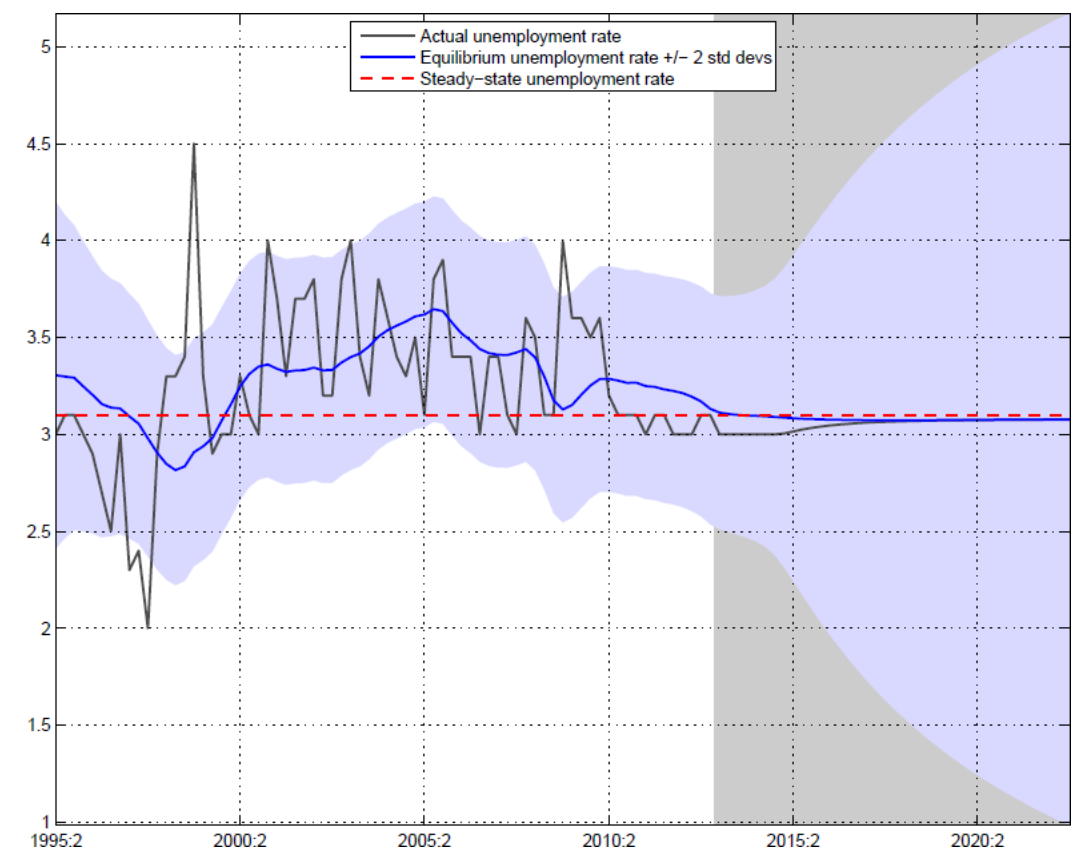

Figure 4. Equilibrium Unemployment Rate (\%)

significantly to a peak of $4.5 \%$, resulting in a large unemployment gap. In general, the equilibrium unemployment rate $^{8}$ moves around the steady state unemployment rate of $3.1 \%$. The equilibrium unemployment rate which is a rather smooth curve suggests that the labor market responded slowly to the changes in the economy. The slow response could be due to the frictions in the labor market. It could also reflect firms' tendency of not firing their workers during the periods of recession, instead the tendency to reduce workers' work hours.

The results of the MVF indicate the possible closing of the unemployment gap and capacity utilization gap in 2017. This is based on the assumptions made in the model, specifically; the steady state growth, unemployment rate and capacity utilization will eventually reach their steady states or long run equilibrium of $5.5 \%, 3.1 \%$ and $80 \%$ respectively ${ }^{9}$ (Figures 3 and 4). When these happen, the output gap, unemployment gap

\footnotetext{
${ }^{8}$ The concept of equilibrium generally applies to the Walrasian equilibrium that is reached when prices adjust to clear the market. That is, when the supply curves intersect the demand curves for all goods in the market. However, this is not the case for dynamic economic models. In dynamic models, there are short-run and long-run equilibria. In the short run, the equilibrium unemployment rate is the NAIRU. In the long run, the speed in which the economy tends toward the equilibrium will depend on the assumptions of the model. In most dynamic models (for example, DSGE), the economy tends toward some "steady state", in which either nothing in the economy is changing, or in which things are only changing at constant long-term trend rates. The economy may or may not ever get to the steady state. But regardless, a steady state is technically a kind of equilibrium as well.

${ }^{9}$ The steady state growth and the steady state unemployment rate of 5.5\% and 3.1\% respectively are estimates obtained from the Tenth Malaysia Plan (10th MP). The $80 \%$ capacity utilization is based on historical average.
} 
and capacity utilization gaps will close, suggesting long-run equilibriums are achievable in all markets and simultaneously, consistency is achieved in the overall system of equations.

Finally, the SVAR and CDPF structural models display similar trajectories but differ in magnitude of fluctuations and at certain point of time show lead-lag effects (Figure 5). For example, although the peaks and the troughs coincide with the turning points of the business cycle, the SVAR estimates the turning point for the downturn during GFC to be in 3Q 2008 and the CDPF approach estimates it to be a quarter later, 1Q 2009. Furthermore, the CDPF shows greater magnitude most of the time compares to SVAR. Such results are in line with Bjornland et al. (2005), Menashe and Yakhin (2004).

The varying degrees of increase and decrease in output gap estimates are due to the characteristics of each method. In SVAR, we have assumed there is a relationship between inflation and output gap while in CDPF, the output gap depends on the level of unemployment, capital stocks and total factor productivity. Hence, the SVAR output gap estimates to an extent move in tandem with the inflation rate (Figure 6). For instance, there was a drop in the inflation rate in Malaysia during the period prior to bubble tech crisis in 2001, hence a declined in the SVAR's output gap estimates. However, the labor share increased in 2000 and both total factor productivity and capital stock were relatively stable (Figure 7). This led to an increase in GDP growth, hence, a positive output gap estimates using CDPF method.

While the output gap profiles produced by the structural models are similar to that of the other approaches, the advantage of using the CDPF method is that, it allows growth to be decomposed into factors of production and productivity (Menashe and Yakhin, 2004). Moreover, (Epstein and Macchiarelli, 2010) argued that pure statistical methods such as the HP filter tend to misidentify boom and bust periods and the extent of fluctuations in growth which are in theory, driven by economic fundamentals.

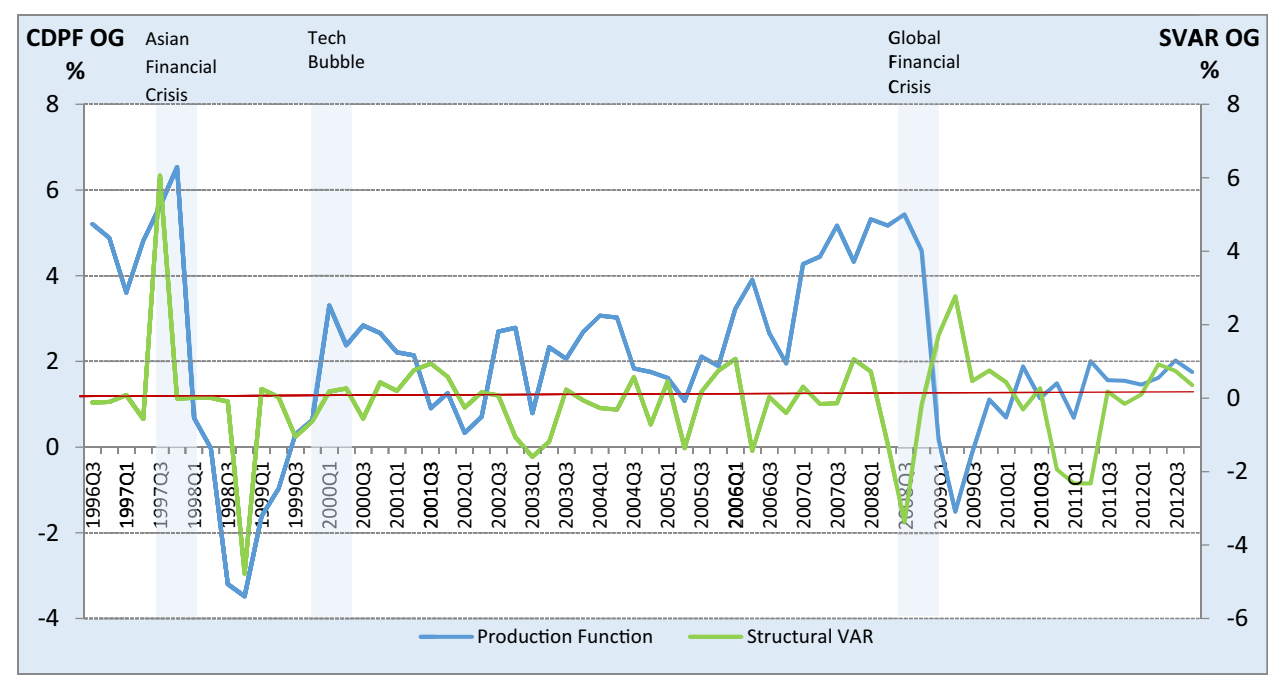

Figure 5. Structural Models' Output Gap Estimates, 1996-2013 


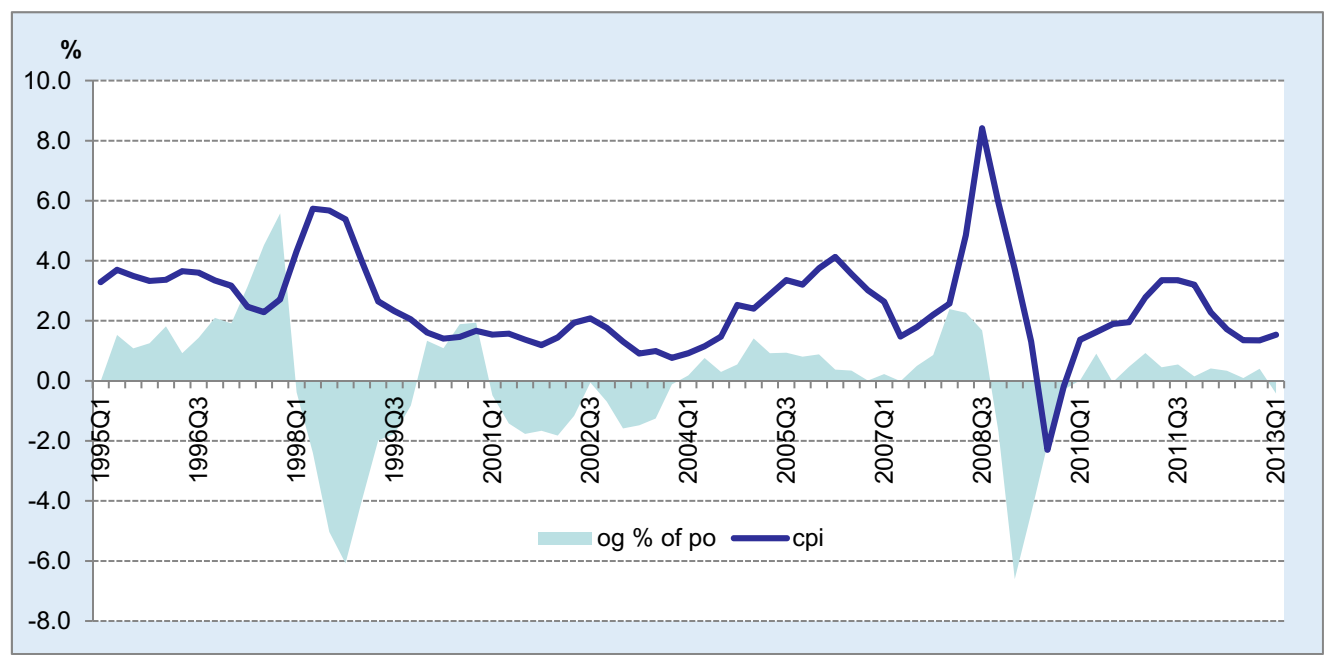

Figure 6. Output Gap Estimates and Inflation in Malaysia, 1995-2013

\subsection{Structural model CDPF and long term drivers of potential output}

While the MVF model is able to provide information on the labor and product markets and, show the evolution of gaps in both markets, it is usually not used to make future projections of the potential output. Policymakers who make such projections usually rely on the CDPF approach, where they combine their projections of labor and capital with views on how productively these factors of production will be used for future production. As structural methods which are underpinned by theory-based assumptions, they can explain

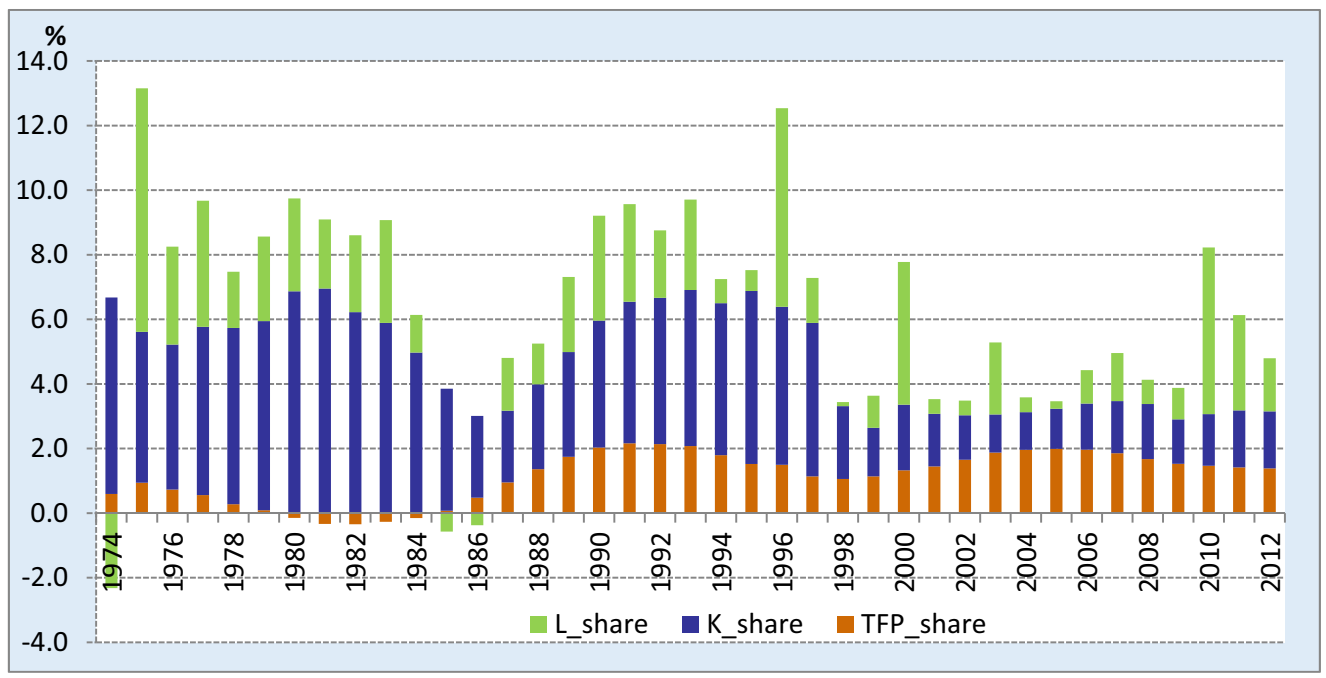

Figure 7. Labor, Capital and Total Factor Productivity Decomposition, 1974-2012 
the drivers of future potential growth better than filtering methods. Filtering methods are mainly derived from trends and their correlation with business cycles.

Therefore, the main usefulness of the CDPF is that, it allows us to breakdown and understands the drivers of production. Based on our CDPF results, we expect the overall potential output to be broadly stable, with the potential output growth ranging between $4.6 \%$ and $5 \%$ in 2014. Potential output growth is expected to be supported by the steady accumulation of capital and stable labor markets. In the longer term, the potential output growth is expected to converge to the steady state of $5.5 \%{ }^{10}$ growth in 2017 (Figure 8). With this convergence, NAIRU is expected to settle at the equilibrium level of $3.1 \%$. However, the evolution of potential output growth and NAIRU precludes any unforeseen shocks to the economy.

In the past, capital input growth made a significant contribution to growth, particularly in the mid-1980s to the mid-1990s, as the country went through a period where heavy industries such as iron and steel, petrochemicals and motor vehicle industries were heavily promoted. As such, growth during this period was mainly driven by capital accumulation. However, investments fell after the AFC and this resulted in a smaller contribution of capital to the growth of potential output (Figure 9).

The average contribution of productivity growth appeared to have declined during and right after the period of economic crises (AFC and GFC). The recovery of productivity appears to be evident after a crisis with its contribution to growth accounting slightly more than a third of potential output growth. Nonetheless, it is still below the contribution of a typical developed country, whose productivity accounts for more than half of its average growth. Anand et al. (2013) suggest that TFP could remain low for the five ASEAN countries for a number of reasons, ranging from low research and development (R\&D) to difficulties in doing business and stringent regulations in the product markets.

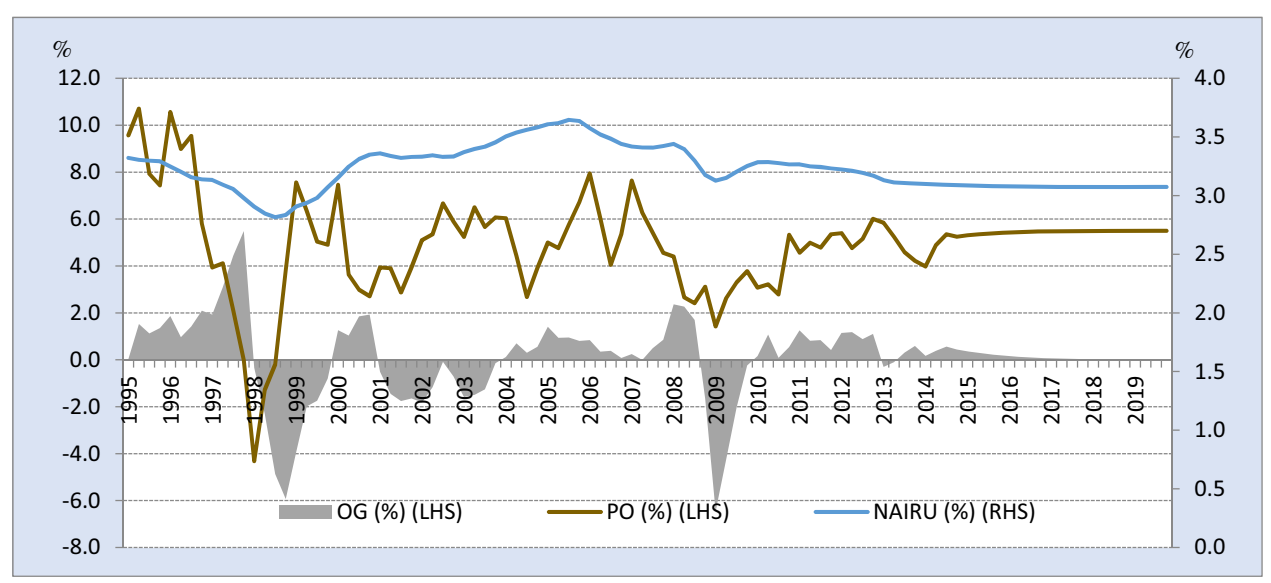

Figure 8. Potential Output Growth, NAIRU and Output Gap, 1995-2019

\footnotetext{
${ }^{10} \mathrm{By}$ construction, the $\mathrm{MV}$ model is expected to converge to the steady state growth for both potential output and unemployment.
} 


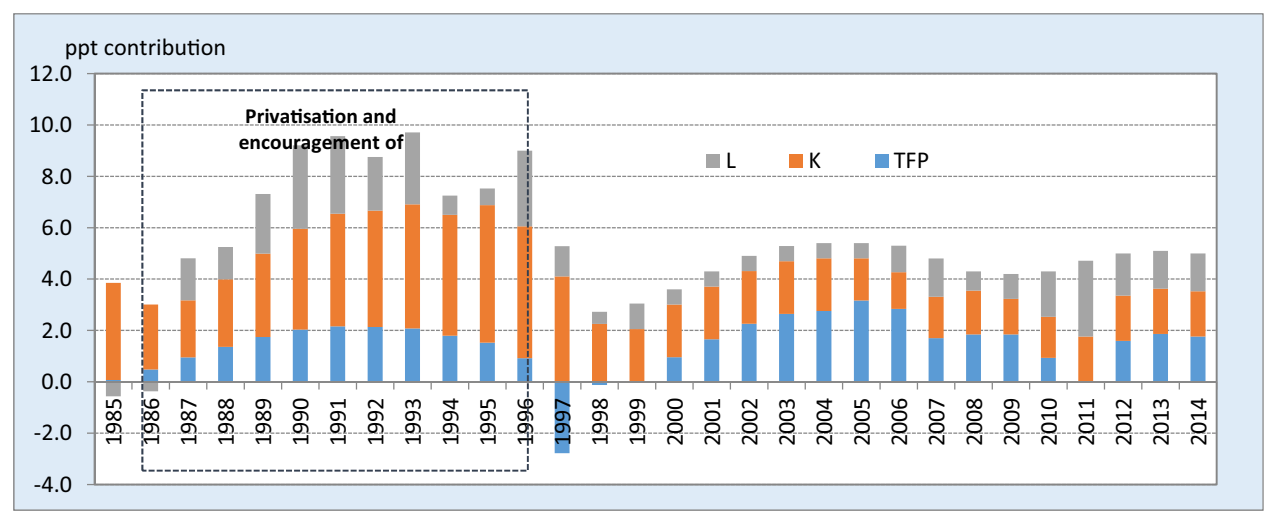

Figure 9. Contributions to Potential Growth, 1985-2014

While the decomposition of past growth rates (Figure 9) shows that Malaysia is still predominantly an input driven economy, there has been a concerted effort to move toward a productivity driven growth. This comes with the realization that the accumulation of capital stock has diminishing returns, and therefore a sustained growth can only be achieved through higher levels of productivity. This is evident in the developed economies where the contribution from TFP usually outpaces the contribution from capital stock by as much as 1.4-4.8 times (Table 1). As TFP is associated with technological innovations and knowledge, an environment which cultivates the accumulation of knowledge and promotes competition is important for the long-term growth of the country.

\subsection{Structural model VAR and sources of inflation}

In Figure 10, we plotted the response of prices to the demand and supply shocks in order to identify the source of inflationary pressure in the economy. During AFC, the inflationary pressure was found to be mainly from the supply shocks as a result of sharp domestic currency depreciation. During the GFC 2008/09, the inflationary pressure was due to the demand shocks. Prior to the crisis, there was a huge demand for credit due to low interest

Table 1. Contribution of the Factors of Production

\begin{tabular}{lcccc}
\hline Malaysia & GDP Growth (\%) & $\begin{array}{c}\text { TFP Growth } \\
\text { (ppt contribution) }\end{array}$ & $\begin{array}{c}\text { Capital Growth } \\
\text { (ppt contribution) }\end{array}$ & $\begin{array}{c}\text { Labor Growth } \\
\text { (ppt contribution) }\end{array}$ \\
\hline 2000-2012 & 5.1 & 1.7 & 1.6 & 1.7 \\
10th MP & 6.0 & 2.3 & 2.3 & 1.4 \\
$\mathbf{1 9 6 0 - 2 0 0 0}$ & & & & \\
Australia & 1.67 & 1.26 & 0.41 & \\
Japan & 3.28 & 2.73 & 0.56 & \\
UK & 1.90 & 1.31 & 0.58 & \\
US & 1.89 & 1.09 & 0.80 & \\
\hline
\end{tabular}

Source: Aghion, PA, 2007 \& authors' calculation. 


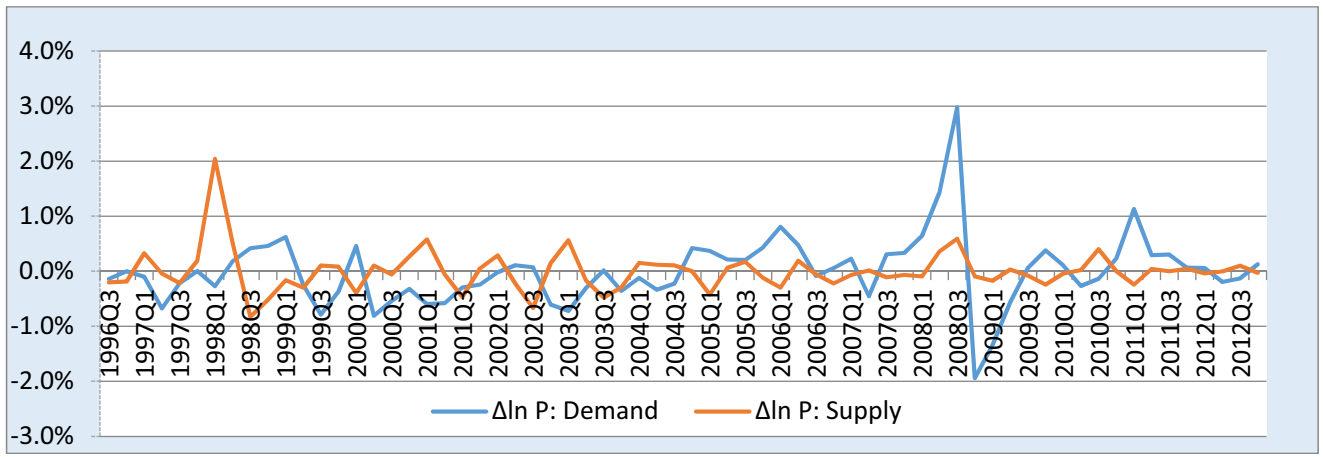

Figure 10. Malaysia's Price Dynamics due to Demand and Supply Shocks (1996Q3-2012Q4)

rate as indicated by a sharp spike in price response to demand shocks. However, there was a credit crunch during the crisis, causing a sharp decline in price response to demand shocks.

\subsection{Output gaps and predicting future price trends}

This section assesses which of the estimated output gaps is more useful in predicting price pressures. In principle, the output gap estimates should be indicative of price pressures in the economy, otherwise, the output gap estimate fails in its objective and usefulness for policy considerations.

For this assessment, we have modified Brouwer and Ericsson's (1995) inflation model which takes into account unit labor cost. However, our modified equation substitutes unit labor $\operatorname{cost}^{11}$ with the producer's price index and oil price (Equation (3.1))

$$
p_{t}=\alpha_{1}+\alpha_{2} p_{t-1}+\alpha_{3} \text { ppi }_{m_{t-1}}+\alpha_{4} \text { dloil }_{t}+\alpha_{5} p_{t-4}+\alpha_{6} o g_{t-1}+\varepsilon_{3 t},
$$

where $p_{t}$ is inflation, $p p i_{m_{t-1}}$ is producer's price for imports, dloil $l_{t}$ is the change in oil price and $o g$ is the output gap $\left(100 * \log\right.$ (actual output - potential output)) and $\varepsilon_{3 t}$ is the error term.

Over a horizon of eight quarters, the forecast for price trend is better when the output gap is included into the price model (Table 2). The improvement of the fit of the model with the different output gap measures over the baseline price model is reflected in the higher adjusted $R^{2}$, with improvements ranging from 5\%-13\%. The largest improvements in explanatory power are seen for price model that uses output gaps derived from the univariate state space and SVAR methods (adjusted $R^{2}$ of 0.762 and 0.759 , respectively).

\footnotetext{
${ }^{11}$ The constructed unit labor cost for Malaysia is only representative of the manufacturing sector. Therefore, modification of Brouwer and Ericsson's model is made with the aim of broadening the representation of cost across all sectors of the economy.
} 
Table 2. A Comparison of the Output Gaps' Predictive Power for Price Trends

\begin{tabular}{|c|c|c|c|}
\hline & $\alpha_{6}$ & Adj $R^{2}$ & RMSE (8 quarters ahead) \\
\hline Baseline & - & 0.674 & 0.899 \\
\hline Linear Trend & $\begin{array}{c}+0.100 * * * \\
(0.036)\end{array}$ & 0.711 & 0.820 \\
\hline Univariate HP & $\begin{array}{c}+0.156^{* * *} \\
(0.042)\end{array}$ & 0.736 & 0.782 \\
\hline Univariate SS & $\begin{array}{c}+0.392 * * * \\
(0.085)\end{array}$ & 0.762 & 0.743 \\
\hline MVKF & $\begin{array}{c}+0.166 * * * \\
(0.050)\end{array}$ & 0.724 & 0.802 \\
\hline Multivariate Filter & $\begin{array}{c}+0.249 * * * \\
(0.056)\end{array}$ & 0.759 & 0.757 \\
\hline SVAR & $\begin{array}{c}+0.324 * * * \\
(0.073)\end{array}$ & 0.760 & 0.764 \\
\hline CDPF & $\begin{array}{c}+0.123 * * * \\
(0.046)\end{array}$ & 0.707 & 0.825 \\
\hline
\end{tabular}

Notes: *Indicates significance at $10 \%$ level, **significance at $5 \%$ level, ***significance at $1 \%$ level. The standard errors are reported in the brackets.

Furthermore, the inclusion of these output gap variables also improved the root mean square error (RMSE) values, which decline between $9 \%$ and $21 \%$. Such improvements are slightly more evident for the univariate state space model and the MVF output gap estimates. $^{12}$ The RMSE improves by $21 \%$ and $18.8 \%$ respectively, from the baseline scenario that excludes the output gap variable in the inflation model.

The results suggest that the univariate state space model appears to be slightly better in explaining current and predicting price trends compared to the other approaches. This is probably due to its ability to trace the business cycle of the economy using the appropriate cosine and sine functions (Equations (A.8) and (A.9) in the appendix). On the other hand, the multivariate filter appears to be slightly better in predicting future inflationary trend relative to explaining the current trend. All the methods show varying degrees of improvement over the baseline model and therefore, suggest that all the output gap measures have information about price trends.

While the ability of the models in predicting future price is an important consideration, the choice of methods for policy formulation involves other considerations. Cotis et al. (2003) argue that the models used for policy consideration must not only be able to provide information which improves the precision of estimates, but they must also be consistent with theory, consistent over time and transparent in their assumptions. Not all models are

\footnotetext{
${ }^{12}$ While $20 \%$ improvement in forecasting may not appear to be significant, it is nonetheless important to a policy maker. A $20 \%$ error could make the forecast of an inflation of $3 \%$ to be $3.6 \%$, and this would have an implication on the policy makers' interest rates decisions.
} 
able to meet these criteria. ${ }^{13}$ For example, the multivariate and structural models may be more consistent with theory compared with the mechanistic univariate method but appears to have performed slightly worse compared to the univariate state space model. In contrast, the univariate state space model which is less transparent appears to slightly outperform the structural models.

The different methods may have passed the analytical test but not one particular model appears to be consistently superior at all fronts such that, it can be consistently selected as a model that can provide a reliable source of information for policy decisions. While maintaining a suite of models has advantages, the risk arising from doing so is that, they can potentially lead to confusion and policy errors (Freedman, 1989). In this respect, most policy makers will take the necessary precaution of communicating the uncertainty surrounding potential output and the output gap estimates and provide a ranged forecast, often in a form of a fan chart. Furthermore, policymakers often do not rely single-handedly on output gap in their decision making. Other indicators such as money and credit growth, housing price, inflation and its expectation, employment, capacity utilization, average hours work, wage growth, housing prices, business and consumer confidence index provide greater support and measures of the overall capacity pressure in the economy (Jahan and Mahmud, 2013). Nonetheless, the diverse results allow the policymakers to contemplate on the various possible outcomes of the output gaps, the risks surrounding its forecasts and its implications on prices.

\section{Policy Implications}

A recent study by the International Monetarty Fund (IMF) showed that potential growth in advanced and other emerging market economies is likely to remain lower than the pre-GFC rates over the medium term. This will have implications on Malaysia's potential growth ${ }^{14}$ and therefore, there is a greater urgency for Malaysia to transit quickly from essentially an input driven economy to a productivity driven economy. In the past, capital and labor contribute about $70 \%$ of GDP growth and TFP contributes the remaining 30\%. While labor and capital remain necessary for production, Malaysia will need a higher total productivity contribution to achieve a sustainable growth. Malaysia's potential output over the medium term would depend on the success of the government's initiatives in accelerating structural reforms that can unleash innovation and enhance long-term competitiveness of the economy.

As such, broad-based initiatives have been developed under the Economic Transformation Program (ETP) to address issues related to productivity and the bottlenecks in the economy. In particular, the government has directed it efforts toward the accelerating of regulatory reforms, rationalizing and enhancing the effectiveness of Government institutions and improving the business climate. In order to raise productivity level further, efforts have also been directed toward lifting labor productivity through up-skilling and re-skilling

\footnotetext{
${ }^{13}$ Although Cheng (2011) found the macro-based MVF model to meet three out of the four criteria outlined by Cotis et al. (2003).

${ }^{14}$ See International Monetary Fund (IMF) World Economic Outlook (WEO), 2015.
} 
of labor, supporting industrial and social innovation activities, tapping on the diaspora of talent, retaining Malaysian-grown talent, and reforming the national education system (Malaysia Education Blueprint, 2013-25).

\section{Conclusion}

The potential output and the output gap play a central role in policy discussions. The policymakers need to assess if the degree of fluctuations in observed output reflects the economy's adjustment to shocks or is reflective of undesirable deviation of output from its time-varying optimal path of output. Such deviations contain information as to how much more the economy can produce and how many more jobs it can create without exerting upward pressure on prices.

However, the output gap is an unobserved variable and its estimation is subject to uncertainty, assumptions and the use of judgment. In this paper, we assess several output gap estimation methods for the Malaysia economy including: (i) univariate methods (linear trend, univariate state space and Hodrick-Prescott (HP) filter models) (ii) multivariate methods (multivariate Kalman filter (MVKF) and macro model-based MVF) (iii) structural methods (CDPF and SVAR). The evolution of the estimation models from a pure statistical approach to a more sophisticated model-based approach has improved our capacity to better capture the inherently unstable nature of potential output.

In this respect, a systematic assessment of the strengths and weaknesses of different models is needed to improve the understanding of the usefulness of each model, particularly for policy decisions. The main observations that can be drawn from this paper are that, in spite of the broadly similar quarterly profiles, the out gaps produce by each models differ. Therefore, the diversity of information from the different gaps if not properly understood may lead to greater confusion and policy errors. Second, the different models have varying degrees of usefulness in terms of predicting price trends, and there is no one which is significantly superior. Although the ability of the models in predicting future price is an important consideration, the choice of methods for policy formulation involves other considerations specified by Cotis et al. (2003). However, in predicting long-term drivers of growth, the CDPF framework which is supported by theory, appears to be a more useful model. The SVAR method can be utilized to identify the source of inflation such that appropriate policies can be implemented to control the inflation.

The diversity in results produced by the different models offers policymaker's different perspectives on the dynamics of growth and the degree of excess capacity and price pressure in the economy. The structural model shows that input driven growth is not sustainable going forward. In this respect, Malaysia like other ASEAN economies, will need to focus on productivity driven growth. Malaysia's Economic Transformation Programme (ETP) which outlines broad-based reforms, encompasses initiatives to improve the business climate, develops quality human capital and raises productivity are crucial in charting the country's long term economic growth. 


\section{Appendix A. Univariate Models}

\section{A.1. Linear trend model}

The linear trend model is the simplest form of estimation technique to extract an underlying trend. Real GDP is regressed on a time variable component which is assumed to increase at a constant rate throughout the sample period (A.1). This may not be a useful model particularly for developing countries, whose potential output increases as their economies develop.

$$
\text { Real GDP }=\beta_{0}+\beta_{1} *(\text { Time })+\varepsilon_{1 t} .
$$

Data: Quarterly real GDP data, 1995Q1-2013Q4, from the CEIC database.

\section{A.2. Univariate Hodrick-Prescott (HP) model}

This is a widely used smoothing procedure to estimate potential output. The model is based on the assumption that the growth component will vary smoothly over time (Hodrik and Prescott, 1997). In this model, the real output is the sum of a trend (potential output) and cyclical component (output gap).

$$
Y_{t}=Y_{t}^{*}+C,
$$

where $Y_{t}=$ Real GDP, $Y_{t}^{*}=$ Potential Output, $C=$ Output Gap.

The idea is to find the value of potential output, $y_{t}^{*}$ that minimizes the loss function $L$, which is, the deviation between actual output and its potential subject to a constraint on the extent to which potential output growth can vary.

$$
\text { Min } \begin{aligned}
L & =\sum_{t=1}^{T} c_{t}^{2}+\lambda \sum_{t=2}^{T}\left(\Delta y_{t}^{*}-\Delta y_{t-1}^{*}\right)^{2} \\
& =\sum_{t-1}^{T}\left(y_{t}-y_{t}^{*}\right)^{2}+\lambda \sum_{t=2}^{T}\left(\Delta y_{t}^{*}-\Delta y_{t-1}^{*}\right)^{2} .
\end{aligned}
$$

The advantage of the HP filter is that it is widely used, straightforward and simple to implement since the only data needed is real GDP. Furthermore, it has the flexibility to make the output gap stationary for a wide range of smoothing values and allows underlying trends to change over time. However, it is difficult to choose $\lambda$, the smoothing parameter and it is usually arbitrary. In this paper, we use the standard value for $\lambda=1600$ for quarterly observations. Another disadvantage of the HP filter is that the variations in actual output at the beginning of the period and at the end of the period affect the level of potential output more than the rest of the period due to the end-point bias (Bjornland et al., 2005).

Data: Quarterly real GDP data, 1995Q1-2013Q4, from the CEIC database. 


\section{A.3. Univariate state space model}

The univariate state space model estimates the unobserved variables of trend and cyclical components from the observed variables, such as real GDP. This model needs to be specified in the state space form since it is a dynamic system model whereby, the observed variable is defined as a function of the unobserved state variables and these unobserved state variables are supported by other separate transition equations. The Kalman filter recursive algorithm will take the assumed initial values of these unobserved state variables, guess its subsequent values and update these guesses based on the prediction errors. This process will continue until all the observations are utilized to produce the best estimators of the unobserved state vectors.

In this paper, the univariate state space model represented by (A.4)-(A.8) decomposes the log of de-seasonalised real GDP into its trend, cycle, and additive noise components. The specification is based on Harvey and Jager (1993).

$$
\begin{gathered}
y_{t}=\mu_{t}+\psi_{t}+\dot{\mathrm{o}}_{t} \quad \dot{\mathrm{o}}_{t} \sim \operatorname{NID}\left(0, \sigma_{\mathrm{o}}^{2}\right), \\
\mu_{t}=\mu_{t-1}+\beta_{t-1}+\eta_{\pi t} \quad \eta_{t} \sim \operatorname{NID}\left(0, \sigma_{\eta}^{2}\right), \\
\beta_{t}=\beta_{t-1}+\varsigma_{t} \quad \varsigma_{t} \sim \operatorname{NID}\left(0, \sigma_{\varsigma}^{2}\right), \\
\psi_{t}=\rho \cos \left(\lambda_{c}\right) \psi_{t-1}+\rho \sin \left(\lambda_{c}\right) \psi_{t-1}+\kappa_{t} \quad \kappa_{t} \sim \operatorname{NID}\left(0, \sigma_{\kappa}^{2}\right), \\
\psi_{t}^{*}=-\rho \sin \left(\lambda_{c}\right) \psi_{t-1}+\rho \cos \left(\lambda_{c}\right) \psi_{t-1}+\kappa_{t}^{*} \quad \kappa_{t}^{*} \sim \operatorname{NID}\left(0, \sigma_{\kappa}^{2}\right),
\end{gathered}
$$

where $y_{t}$ is the real GDP, $\mu_{t}$ is the trend component (output potential), $\psi_{t}$ is the cyclical component (output gap), $\beta_{t}$ is the increase in potential output, $o_{t}, \eta_{t}, \zeta_{t}, \kappa_{t}$ are additive noises and mutually independent, $\rho$ is the damping factor, $\lambda_{c}$ is the peak of the spectral density ${ }^{15}$ corresponding to the period of $2 \pi / \lambda_{c}$. In identifying the value of $\rho$ and $\lambda_{c}$, we follow Proietti (2002) in assuming that the reduced form of the cycle, $\psi_{t}$ is ARMA $(2,1)$ process:

$$
\begin{gathered}
\left(1-\emptyset_{1} L-\emptyset_{2} L^{2}\right) \Psi_{t}=\left(1-\rho \cos \lambda_{c} L\right) \kappa_{t}+\rho \sin \lambda_{c} \kappa_{t-1}^{*}, \\
\emptyset_{1}=2 \rho \cos \lambda_{c}, \quad \emptyset_{2}=-\rho^{2} .
\end{gathered}
$$

Solving these equations, we obtain $\rho=0.7$ and $\lambda_{c}=0.52$. When the damping factor $\rho$ is big, the more the peaks and the valleys are smoothed out. Using spectral density of $\lambda_{c}=0.52$, we can calculate the period of business cycle $\left(2 \pi / \lambda_{c}\right)$ and in this model, it is 12 quarters (short term business cycles). The advantage of this method is that it can be applied to a non-linear system and multiple input and output system. However, it is very sensitive to the specification of the model, including the initial values of the unobserved variables, estimation period and the estimated parameters $\rho$ and $\lambda_{c}$ (Anand et al., 2014). Furthermore, it suffers from state explosion problem, even a relatively small descriptions in the system can cause an infinite number of reachable states.

\footnotetext{
${ }^{15}$ Spectral density is the Fourier transformation of the autocorrelation in the data and ultimately converts any signal to its sine and cosine term.
} 
Data: Quarterly real GDP data, 1995Q1-2013Q4, from the CEIC database.

\section{Appendix B. Multivariate Models}

The multivariate or semi structural methods treat the filtering problem as a dynamic system whereby blocks of economic equations that create economic structure are estimated simultaneously using certain statistical specifications. There are two multivariate models presented here: (i) Multivariate Kalman filter and; (ii) macro model-based MVF. The main idea using multivariate methods is that the variation in GDP is influenced by the variation in other key macroeconomic variables. For example, the MVF strives to bring consistency between the estimated potential output growth with the non-accelerating inflation rate of unemployment (NAIRU) and the stable inflation (Benes et al., 2010). The multivariate Kalman filter exploits information on excess demand in labor and product markets as conditions to estimate potential output. However, they lack transparency in a sense that the estimation process is not straightforward and we cannot immediately dissect the relationship between various factors and trend growth (Anand et al., 2014).

\section{B.1. Multivariate Kalman filter}

This model follows from Konuki (2008) who treats the filtering problem as a dynamic system in estimating potential output and the relevant parameters simultaneously. The idea is that a wage hike should give some information on the degree of excess demand in the labor market which is most likely due to the excess demand in the goods market. In this model, the specification of the dynamic system is written in the state space form in which Equation (B.1) is the signal equation and Equations (B.2)-(B.5) are the transition equations:

$$
\begin{gathered}
Y_{t}=\bar{Y}_{t}+y \operatorname{gap}_{t}, \\
\bar{Y}_{t}=\bar{Y}_{t-1}+\mu_{t-1}+\bar{\varepsilon}_{t}^{y}, \\
\mu_{t}=\beta \mu_{t-1}+(1-\beta) \bar{\mu}_{t}+\varepsilon_{t}^{\mu}, \\
y \operatorname{gap}_{t}=\propto_{0} y \operatorname{gap}_{t-1}+\propto_{1} y \operatorname{gap}_{t-1}^{f}+\varepsilon_{t}^{y g a p}, \\
\Delta^{2} \mathrm{ULC}_{t}=\theta_{0}+\theta_{1} y \operatorname{gap}_{t}+\varepsilon_{t}^{w}
\end{gathered}
$$

$Y_{t}$ is the log of seasonally adjusted quarterly real GDP, $\bar{Y}_{t}$ is potential output, $y \mathrm{gap}_{t}$ is the output gap, $\mu_{t}$ is the quarter on quarter growth rate of potential output, $\bar{\mu}_{t}$ is the fixed steady state rate of quarter-on-quarter growth, $y g^{\prime} p_{t}^{f}$ is the export market output gap, $\Delta^{2} \mathrm{ULC}_{t}$ is the change in the growth rate of nominal unit labor costs. The error terms in (B.1)-(B.5) are assumed to be independent and identically distributed (i.i.d) random variables from a normal distribution. The advantage of this model is the consideration of economic links between the output gap and other economic indicators. However, the disadvantage is that the parameter estimates need to be initialized and the results are sensitive to the choice of starting values. 
Data: Quarterly real GDP data of Malaysia and its top 10 trading partners, ${ }^{16} 1995$ Q12013Q4, from the CEIC database. Nominal unit labor cost is from Bank Negara Malaysia's database.

\section{B.2. Multivariate filter}

We use the model developed by Benes et al. (2010), which incorporates economic structure such that the estimation of the output gap depends on three blocks of equations: the price block, the unemployment block and the capacity utilization block (Figure B.1). These three economic blocks are inter-related and form close relationship, such that the estimation of the potential output will incorporate the information generated from the blocks' corresponding gaps namely, the output gap $(y)$, unemployment gap $(\mu)$ and capacity utilization gap $(c)$. For example, the inflation equation relates the output gap to inflation (Equation (B.7)), Okun's law relates the output gap to unemployment gap (Equation (B.9)) and the capacity utilization equation relates the output gap to capacity utilization gap (Equation (B.11)).

One of the advantages of this filter is that it is more robust to end-point revisions and estimates potential output and the NAIRU simultaneously (Benes et al., 2010). However, as pointed out in other studies, this model cannot be used for estimating the future trend growth since by construction it will converge to the assumed steady-state growth rate.

The output gap $\left(y_{t}\right)$ is defined as the log difference between actual output $\left(Y_{t}\right)$ and potential output $\left(\bar{Y}_{t}\right)$

$$
y_{t}=100 * \log \left(Y_{t} / \bar{Y}_{t}\right) .
$$

The output gap $\left(y_{t}\right)$ affects headline inflation $\left(\pi 4_{t}\right)$ in this augmented Philip's curve

$$
\pi 4_{t}=\pi 4_{t-1}+\beta y_{t}+\Omega\left(y_{t}-y_{t-1}\right)+\varepsilon_{t}^{\pi 4} .
$$

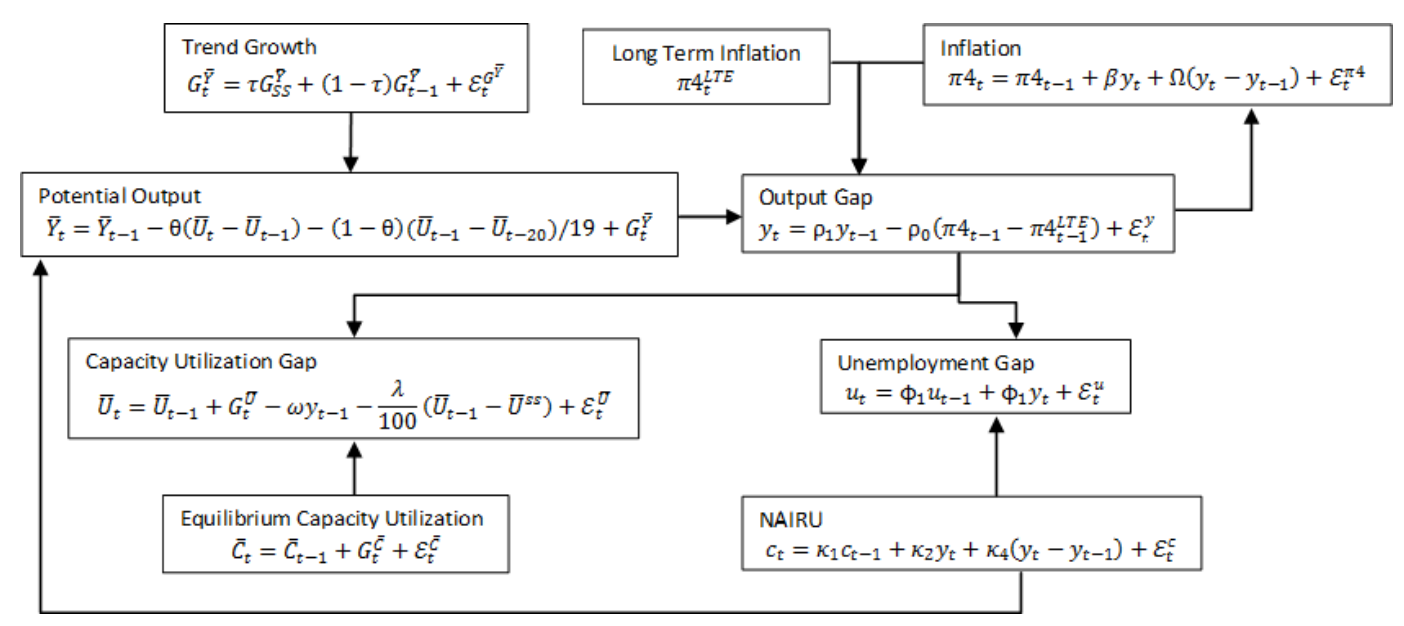

Figure B.1. The Interactions of Economic Theory to Estimate Output Gap

\footnotetext{
${ }^{16}$ Malaysia's major trading partners are China, Germany, Hong Kong, Indonesia, Japan, Korea, Singapore, Thailand, USA and others are listed on the Official Portal of Malaysia External Trade Development Corporation, MATRADE.
} 
The unemployment gap $\left(\mu_{t}\right)=$ equilibrium unemployment/NAIRU $\left(\bar{U}_{t}\right)-$ actual unemployment.

$$
\mu_{t}=\bar{U}_{t}-U_{t-1}
$$

The output gap affects the unemployment gap

$$
\mu_{t}=\Phi_{1} \mu_{t-1}+\Phi_{2} y_{t}+\varepsilon_{t}^{\mu}
$$

Capacity utilization gap $\left(c_{t}\right)=$ actual capacity utilization $\left(C_{t}\right)$ - equilibrium capacity utilization $\left(\bar{C}_{t}\right)$.

$$
c_{t}=C_{t}-\bar{C}_{t} .
$$

The output gap $\left(y_{t}\right)$ affects the capacity utilization gap $\left(c_{t}\right)$

$$
c_{t}=K_{1} c_{t-1}+K_{2} y_{t}+K_{4}\left(y_{t}-y_{t-1}\right)+\varepsilon_{t}^{c} .
$$

The stochastic process for equilibrium unemployment $\left(\bar{U}_{t}\right)$ includes steady state unemployment $\left(U^{s s}\right)$ and two shocks: pure level shocks $\left(\varepsilon_{t}^{\bar{\mu}}\right)$ and persistent shocks $\left(G_{t}^{\bar{\mu}}\right)$

$$
\bar{U}_{t}=\bar{U}_{t-1}+G_{t}^{\bar{\mu}}-\omega y_{t}-\frac{\lambda}{100}\left(\bar{U}_{t-1}-U^{s s}\right)+\varepsilon_{t}^{\bar{\mu}} .
$$

The stochastic process for persistent shocks:

$$
G_{t}^{\bar{\mu}}=(1-\alpha) G_{t-1}^{\bar{\mu}}+\varepsilon_{t}^{G^{\bar{u}}} .
$$

The stochastic process for potential output $\left(\bar{Y}_{t}\right)$ is correlated with changes in equilibrium unemployment and the underlying trend growth rate of potential output

$$
\bar{Y}_{t}=\bar{Y}_{t-1}-\theta\left(\bar{U}_{t}-\bar{U}_{t-1}\right)-\frac{(1-\theta)\left(\bar{U}_{t}-\bar{U}_{t-20}\right)}{19}+G_{t}^{\bar{Y}} .
$$

The underlying trend growth rate of potential output $\left(G_{t}^{\bar{Y}}\right)$ depends on steady state growth rate $\left(G_{s s}^{\bar{Y}}\right)$

$$
G_{t}^{\bar{Y}}=\tau G_{s s}^{\bar{Y}}+(1-\tau) G_{t-1}^{\bar{Y}}+\varepsilon_{t}^{G^{\bar{Y}}} .
$$

The stochastic process for the output gap $\left(y_{t}\right)$ depends on the difference of inflation and the perceived long-term target $\left(\pi 4_{t-1}-\pi 4_{t-1}^{L T E}\right)$

$$
y_{t}=\rho_{1} y_{t-1}-\rho_{0}\left(\pi 4_{t-1}-\pi 4_{t-1}^{L T E}\right)+\varepsilon_{t}^{y} .
$$

The stochastic process for perceived long-term inflation $\left(\pi 4_{t}^{L T E}\right)$ depends on its lag

$$
\pi 4_{t}^{L T E}=\pi 4_{t-1}^{L T E}+\varepsilon_{t}^{\pi 4^{L T E}} .
$$

The stochastic process for equilibrium capacity utilization $\left(\bar{C}_{t}\right)$ consists of two shocks: pure level shocks and persistent shocks.

$$
\bar{C}_{t}=\bar{C}_{t-1}+G_{t}^{\bar{C}}+\varepsilon_{t}^{\bar{C}} .
$$

Equations (B.6)-(B.18) are estimated using Bayesian methodology, specifically by applying the regularized maximum likelihood method. In using this method, we have to 
Table B.1. Maximum Regularized Likelihood (Priors and Posteriors)

\begin{tabular}{lccccc}
\hline & \multicolumn{2}{c}{ Prior } & & \multicolumn{2}{c}{ Posterior } \\
\cline { 2 - 3 } \cline { 6 - 6 } Parameter & Mode & Dispersion & & Mode & Dispersion \\
\hline $\boldsymbol{G}_{\boldsymbol{S S}}^{\bar{Y}}$ & 5.50 & 1.00 & & 5.50 & 1.00 \\
$\boldsymbol{U}^{S S}$ & 3.10 & 1.00 & & 3.10 & 1.00 \\
$\alpha$ & 0.10 & 0.16 & & 0.50 & 0.17 \\
$\beta$ & 0.20 & 0.03 & & 0.17 & 0.04 \\
$\omega$ & 0.10 & 0.03 & & 0.03 & 0.04 \\
$\Phi 1$ & 0.90 & 0.16 & & 0.81 & 0.08 \\
$\rho 1$ & 0.20 & 0.03 & & 0.19 & 0.04 \\
$\rho 1$ & 0.40 & 0.03 & & 0.18 & 0.04 \\
$\tau$ & 0.18 & 0.03 & & 0.22 & 0.05 \\
$\delta$ & 0.10 & 0.16 & & 0.22 & 0.16 \\
$\Phi 2$ & 2.00 & 0.32 & & 1.00 & 1.00 \\
$\lambda$ & 2.00 & 0.32 & & 1.00 & 1.00 \\
\hline
\end{tabular}

specify the priors of the parameters used to prevent these parameters from breaching implausible range (Table B.1). ${ }^{17}$ Hence, we estimated those equations with parameters using OLS regression, independently and used the estimated coefficients as the basis in specifying the priors. The steady state growth $G_{s s}^{Y}$ value is $5.5 \%$ and the steady state unemployment rate $U^{s s}$ is $3.1 \%$ following averages of the official targets in the Tenth Malaysia Plan (10th MP). ${ }^{18}$ For this particular method to converge, it needs targeted values in the form of steady state growth and unemployment rate which are estimated outside the model.

Data: Quarterly real GDP, consumer price index $(2005=100)$, capacity utilization and unemployment rate data, 1995Q1-2013Q4, are from the CEIC database.

\section{Appendix C. Structural Methods}

The structural methods are underpinned by economic theory that links potential output to other macroeconomic variables. Unlike the univariate and multivariate methods that decompose GDP into its trend and cycle (gap) components, the CDPF decomposes growth into contributions by factor inputs while the SVAR decomposes GDP and price into demand and supply shocks. Potential output and the output gap are derived using the information extracted from the decomposition results in these models. Instead of only assessing the final values, these techniques allow us to examine the underlying factors

\footnotetext{
${ }^{17}$ However, as pointed out by Benes et al. (2010), the choice of the prior has minimal significant impact on the final estimates since the data are uninformative of several parameters.

${ }^{18}$ The Tenth Malaysia Plan 2011-2015 is published on the EPU website: http://www.epu.gov.my/en/tenth-malaysia-plan10th-mp-.
} 
that drive the changes in potential output, thereby adding depth to the interpretation of the results. For example, the growth accounting exercise in the CDPF approach decomposes potential output growth into contributions from labor, capital and total factor productivity.

A shortcoming of the CDPF model is that, it relies on univariate methods to detrend some of the variables used in the computation process, such as trended labor and capital stock (Bjornland et al., 2005). Therefore, the weaknesses inherent in the univariate methods may also affect the estimation process of the CDPF model. Furthermore, the structural methods utilize large amount of information and could be a constraint if the data is limited (Almeida and Felix, 2006).

\section{C.1. Production function}

The theoretical foundation of this approach is the neoclassical growth model (Solow, 1956). The advantages of the production function approach are its flexibility and ability to decompose growth attributable to factors of production such as capital, labor and total factor productivity. The decomposition will allow us to derive the relative contributions of these factors in generating potential output.

The production approach uses the CDPF with two factors of input, namely, capital $(K)$, labor $(L)$ and technological progress $(A)$ :

$$
Y_{t}=A_{t} K_{t}^{1-\alpha} L_{t}^{\alpha}
$$

$Y_{t}$ is output (real GDP), $A_{t}$ is total factor productivity, $K_{t}$ is capital stock and $L_{t}$ is labor. The partial elasticity coefficients of labor, $\alpha$ and capital $(1-\alpha)$ are estimated using a simple OLS equation below:

$$
\Delta \ln y_{t}=(1-\alpha) \Delta \ln k_{t}+\alpha \Delta \ln l_{t} .
$$

The partial elasticities with respect to labor and capital can be equated to the wage share and the income on capital, respectively. Based on Equation (C.2), the results of our labor share $\alpha$ is 0.58 and capital $(1-\alpha)$ is 0.42 .

The estimation of potential output is done in three stages. First, the Solow residual (total factor productivity) is derived as output minus the weighted sum of labor and capital inputs. The trends of capital and total factor productivity are generated using the HP filter. Second, the trend for labor derived from the NAIRU equation is estimated using the Kalman filter.

The NAIRU model is as follows:

$$
\begin{gathered}
\Delta \pi_{t}=\alpha_{1} \Delta \pi_{t-1}+\alpha_{2} u \operatorname{gap}_{t}+\alpha_{3} Z_{t}+\varepsilon_{1 t}, \\
u_{t}=u \operatorname{gap}_{t}+u_{t}^{*}, \\
u_{t}^{*}=u_{t-1}^{*}+\varepsilon_{2 t}, \\
u \operatorname{gap}_{t}=u \operatorname{gap}_{t-1}+\alpha_{4} y \operatorname{gap}_{t}+\varepsilon_{3 t}
\end{gathered}
$$

(Benes and N'Diaye (2004)) $\pi_{t}$ is inflation, $u$ gap $_{t}$ is unemployment gap, $u_{t}$ is actual unemployment rate, $u_{t}^{*}$ is the NAIRU, $y$ gap is output gap and $Z_{t}$ are supply side shock 
variables such as imported prices, energy prices and the deviation of productivity from its trend. In this paper, we employ imported prices to estimate NAIRU and potential employment is estimated as (1-NAIRU/100)*level of employment.

In the third stage of estimating potential output, the trends of the three components of growth, namely total factor productivity, labor and capital are plugged into Equation (C.1) to obtain potential output.

Data: Quarterly real GDP, 1995Q1-2013Q4, is from the CEIC database. Capital stock and labor force data are from Department of Statistics Malaysia (DOSM). For the capital stock data, we used log-linear to convert the low frequency data (annually) to higher frequency data (quarterly). In the years where the data are unavailable, we employed perpetual inventory method to estimate the missing values. ${ }^{19}$

\section{C.2. Structural vector autoregression (SVAR)}

This model was first proposed by Blanchard and Quah $^{20}$ (1989) who estimated the SVAR model using GDP and unemployment. The basic idea is to decompose the random disturbances into two components, namely, a permanent component determined by supply shocks or disturbances and, a transitory/temporary component determined by demand shocks. The response of output to demand side shocks will dissipate in the long run while its response to supply side shocks will have a permanent effect. This is done in the model by imposing long term-constraints on the transitory demand disturbances. The SVAR approach to estimate the output gap has been applied among others, by Bjornland et al. (2005), and Menashe and Yakhin (2004).

\section{C.2.1. Blanchard \& Quah decomposition in estimating the potential output}

Let $Y_{t}=(\Delta \ln \text { GDP, Inflation })^{T}$.

Assume that $Y_{t}$ is explained by the following linear dynamic structural model:

$$
\begin{gathered}
Y_{t}=B_{0} Y_{t}+B_{1} L Y_{t}+\cdots+B_{p} L^{p} Y_{t}+V_{t} \\
E\left(V_{t} V_{t}^{T}\right)=\Omega=\left[\begin{array}{cc}
\omega_{11} & 0 \\
0 & \omega_{22}
\end{array}\right] \text { and } B_{0}=\left[\begin{array}{cc}
0 & b_{10} \\
b_{20} & 0
\end{array}\right]
\end{gathered}
$$

$B_{0}, B_{1}, B_{2}, \ldots, B_{p}$ are unrestricted parameter matrices; $V_{t}$ are the residuals with diagonal matrix $\Omega ; L$ is the lag operator; $p$ is the number of lags that are included in the model. Assume that $p$ is large enough such that $V_{t}$ is white noise. ${ }^{21}$ The zero restrictions in $B_{0}$ and $\Omega$ are convenient normalizations (Lastrapes, 1992).

The data can only recover the unrestricted reduced form of the structural model. Rewriting (C.7) in the following form allows us to estimate the $\operatorname{VAR}(p)$ model.

\footnotetext{
${ }^{19}$ The perpetual inventory method takes the previous year capital stock plus current year investment flow minus the current year depreciation values. This approach follows Meinen, Verbiest and Wolf (1998).

${ }^{20} \mathrm{~B} \& \mathrm{Q}$ hereafter

${ }^{21} V_{t}$ here is assumed to be of the same dimensionality as $Y_{t}$ although, $V_{t}$ can be a function of multiple underlying shocks. As long as $Y_{t}$ is stationary, the structural model can be represented as in (C.7), (Lastrapes (1992), B\&Q (1989)).
} 


$$
\begin{gathered}
Y_{t}=\left(I-B_{0}\right)^{-1} B_{1} L Y_{t}+\cdots+\left(I-B_{0}\right)^{-1} B_{p} L^{p} Y_{t}+\left(I-B_{0}\right)^{-1} V_{t}, \\
Y_{t}=A_{1} L Y_{t}+\cdots+A_{p} L^{p} Y_{t}+e_{t}, \\
E\left(e e^{T}\right)=\sum=\left[\begin{array}{ll}
\sigma_{11}^{2} & \sigma_{12} \\
\sigma_{21} & \sigma_{22}^{2}
\end{array}\right] .
\end{gathered}
$$

Since, $E\left(e e^{T}\right)=\sum=\left(I-B_{0}\right)^{-1} \Omega\left(I-B_{0}\right)^{-T}$

$$
\left(I-B_{0}\right) \sum\left(I-B_{0}\right)^{T}=\Omega .
$$

Therefore, we need to identify $B_{0}$ in order to solve (C.10).

$$
\left[\begin{array}{cc}
1 & -b_{10} \\
-b_{20} & 1
\end{array}\right]\left[\begin{array}{cc}
\sigma_{11}^{2} & \sigma_{12} \\
\sigma_{21} & \sigma_{22}^{2}
\end{array}\right]\left[\begin{array}{cc}
1 & -b_{20} \\
-b_{10} & 1
\end{array}\right]=\left[\begin{array}{cc}
\omega_{11} & 0 \\
0 & \omega_{22}
\end{array}\right] \text {. }
$$

There are three restrictions imposed by Equation (C.11) on the four unknowns $b_{10}, b_{20}, \omega_{11}, \omega_{22}$ :

$$
\begin{gathered}
\sigma_{11}^{2}-2 b_{10} \sigma_{21}+b_{10}^{2} \sigma_{22}^{2}-\omega_{11}=0, \\
-b_{20} \sigma_{11}^{2}+\left(1+b_{10} b_{20}\right) \sigma_{12}-b_{10} \sigma_{22}^{2}=0, \\
b_{20}^{2} \sigma_{11}^{2}-2 b_{20} \sigma_{21}+\sigma_{22}^{2}-\omega_{22}=0 .
\end{gathered}
$$

Since we have three non-linear equations on four unknowns, the identification problem is clear. Hence, we need an additional restrictions on $B_{0}$ or $\Omega$ for identification purpose.

Assume that $\operatorname{VAR}(p)$ in Equation (C.9) for $Y_{t}$ is stable. This means that the roots of characteristics polynomial are outside the unit circle. Then, we can invert the $\operatorname{VAR}(p)$ model into moving average representation, $\mathrm{MA}(\infty)$.

$$
Y_{t}=\left(I-A_{1} L Y_{t}-\cdots-A_{p} L^{p} Y_{t}\right)^{-1} e_{t}=\left[\begin{array}{ll}
a_{11}(L) & a_{12}(L) \\
a_{21}(L) & a_{22}(L)
\end{array}\right]\left(I-B_{0}\right)^{-1} V_{t},
$$

where $a_{11}(L), a_{12}(L), a_{21}(L), a_{22}(L)$ is an infinite order lag polynomial. ${ }^{22}$

Based on B\&Q's assumption, these structural residuals can be decomposed into two orthogonal shocks, temporary and permanent. This implies that there is no long-run effects from aggregate demand shocks on the growth of output since aggregate demand shocks are transitory. Our output will go back to its natural rate of output. Thus, from (C.15), the additional constraint is:

$$
\frac{\sum_{j=1}^{\infty} a_{11, j}}{\left(1-b_{10} b_{20}\right)}+\frac{\sum_{j=1}^{\infty} a_{12, j} b_{20}}{\left(1-b_{10} b_{20}\right)}=0
$$

\footnotetext{
${ }^{22}$ The values of $A(L)$ and variance-covariance of $e_{t}$ are obtained from the $\operatorname{VAR}(p)$ estimates in Equation (C.10). $\left(I-B_{0}\right)^{-1}=\left[\begin{array}{cc}1 & -b_{10} \\ -b_{20} & 1\end{array}\right]^{-1}=\left[\begin{array}{cc}1 / \Delta & b_{10} / \Delta \\ b_{20} / \Delta & 1 / \Delta\end{array}\right]$ where $\Delta=\left(1-b_{10} b_{20}\right)$
} 
Now, we can solve for Equations (C.12)-(C.14). The output gap is the cumulative response of output to the demand shocks and potential output is the cumulative response of output to supply shocks (or actual output minus the output gap).

Data: Quarterly real GDP and consumer price index (2005=100) data, 1995Q1-2013Q4, are from the CEIC database.

\section{References}

Abiad, A, R Balakrishnan, P Koeva Brooks, D Leigh and I Tytell (2009). What's the damage: Medium-term output dynamics after financial crises. IMF Working Paper (WP 09/245), 37.

Adamu, P, M Iyoha and E Kouassi (2009). Estimating potential output of Nigeria: Structural VAR approach. In 19th Annual Conf. of the African Econometric Society on Econometric Analysis and Policy Challenges in Africa, p. 26. Africa: African Econometrics Society in collaboration with the Ethiopian Economics Association (EEA).

Aghion, PA (2007). Capital, innovation, and growth accounting. Oxford Review of Economic Policy, 23(1), 79-93.

Almeida, V and R Felix (2006). Computing potential output and the output gap for the Portuguese economy. Economic Bulletin and Financial Stability Report Articles, Banco de Portugal, 73-88.

Anand, R, K Cheng, S Rehman and L Zhang (2014). Potential growth in emerging Asia. IMF Working Paper, 28.

Babihuga, R (2011). How large is Sweden's output gap. Sweden: 2011 Article IV Consultation-Staff Report; Public Information Notice on the Executive Board Discussion and Statement by the Executive Director for Sweden, 44.

Bank Negara Malaysia (2012). Potential Output and the Output Gap in Malaysia. Bank Negara Malaysia, Economics Department. Kuala Lumpur: Quarterly Bulletin Second Quarter.

Bautista, CC (2002). Estimates of output gaps in four Southeast Asian countries. Economics Letters, 80(3), 11.

Benes, J and P N'Diaye (2004). A multivariate filter for measuring potential output and the NAIRU: Application to The Czech Republic. IMF Working Paper, 31.

Benes, J, D Laxton, K Clinton, R Garcia-Saltos, M Johnson, P Manchev and T Matheson (2010). Estimating potential output with a multivariate filer. IMF Working Paper, 37.

Billi, R (2012). Output gaps and robust monetary policy rules. Sveriges Riksbank, Working Paper Series, 27.

Bjornland, HC, L Brubakk and AS Jore (2005). The output gap in Norway - a comparison of different methods. Economic Bulletin, 05 Q2, 11.

Blanchard, OJ and D Quah (1989). The dynamic effects of aggregate demand and supply disturbances. American Economic Review, 79, 665-673.

Bokan, N and R Ravnik (2012). Estimating potential output in the Republic of Croatia using a multivariate filter. CNB Occasional Pulications - Working Papers, W-35, 19.

Borio, C, P Disyatat and M Juselius (2013). Rethinking potential output: Embedding information about the financial cycle. BIS Working Papers No. 404.

Brouwer, G (1998). Estimating output gaps. Reserve Bank of Australia Research Discussion Paper 9809, 35.

Brouwer, G and N Ericsson (1995). Modelling inflation in Australia. Research Discussion Paper 9508, Reserve Bank of Australia, 70.

Bruchez, P (2003). A modification of the HP filter aiming at reducing the end-point bias. Swiss Federal Finance Administration Working Paper, 20. 
Chagny, O and J Döpke (2001). Measures of the output gap in the Euro-Zone: An empirical assessment of selected methods. Kiel Working Paper No. 1053, 40.

Cheng, K (2011). France's potential output during the crisis and recovery. International Monetary Fund. Washington D.C: France: Selected Issues Paper, IMF Country Report No. 11/212.

Cheng, M, L Chung and I-W Yu (2011). On the estimation of the output gap of Hong Kong. Hong Kong Monetary Authority Occasional Paper 03/2011, 29.

Claus, I, P Conway and A Scott (2000). The output gap: Measurement, comparisons and assessment. Research Paper (44), 1-68.

Cotis et al. JE (2003). Estimates of potential output: Benefits and pitfalls from a policy perspective. OECD Working Paper, 1-27.

Epstein, N and C Macchiarelli (2010). Estimating Poland's potential output: A production function approach. IMF Working Paper (10/15), 1-12.

Felipe, J, NR Sotocinal and C Bayudan-Dacuycuy (2015). The impact of financial factors on the output gap and estimates of potential output growth. ADB Economics, Working Paper Series, No. 457.

Freedman, C (1989). Monetary policy in the 1990s: Lessons and challenges. In Monetary Policy Issues in the 1990s, Symp. of the Federal Reserve Bank of Kansas City, pp. 1-45. Kansas City, Federal Reserve Bank of Kansas City.

Gamber, E (1996). Empirical estimates of the short run aggregate supply and aggregate demand curves for the post war US economy. Southern Economic Journal, 62, 856-872.

Harvey, A and A Jager (1993). Detrending, stylized facts and the business cycle. Journal of Applied Econometrics, 8(3), 231-247.

Hodrick, RJ and EC Prescolt (1997). Postwar US business cycles: An empirical investigation. Journal of Money, Credit and Banking, 29(1), 1-16.

Isnawangsih, A, V Klyuev and L Zhang (2013). The big split: Why did output trajectories in the ASEAN-4 Diverge after the global financial crisis? IMF Working Paper, 17.

Jahan, S and A Mahmud (2013). International Monetary Fund. Retrieved from Back to Basics: Finance and Development, Vol. 50, No. 3. Available at: http://www.imf.org/external/pubs/ft/ fandd/2013/09/basics.htm.

Konuki, T (2008). Estimating potential output and the output gap in Slovakia. IMF Working Paper, 20.

Koopman, GJ and IP Szekely (2009). The financial crisis and potential growth: Policy challenges for Europe. European Economic Brief, Issue 3.

Lastrapes, WD (1992). Sources of fluctuations in real and nominal exchange rates. Review of Economics and Statistics, 20, 530-39.

Lee, $\mathrm{H}$ and Y Khatri (2001). Potential output and inflation. International Monetary Fund Occasional Paper 207, 28-38.

McMorrow, K and W Roeger (2001). Potential Output: Measurement Methods, "New" Economic Influences and Scenarios for 2001-2010 - A Comparison of the EU-15 and the US. ECFIN Economic Paper (150), 1-142.

Meinen, G, P Verbiest and PD Wolf (1998). Perpetual Inventory Method-Service Lives, Discard Patterns and Depreciation Methods, pp. 1-55. Statistics Netherlands, Department of National Accounts.

Menashe, Y and Y Yakhin (2004). Mind the gap: Structural and nonstructural approaches to estimating Israel's output gap. Israel Economic Review, 2(2), 79-106.

Mishkin, F (2007). Estimating potential output. In Conf. of Price Measurement for Monetary Policy. p. 6. Texas: Federal Reserve Bank of Dallas.

Proietti, T (2002a). Forecasting with structural time series models, in Clements, MP and DF Hendry (eds), A Companian to Economic Forecasting, Blackwell Publishers, Oxford, pp. 105-132. 
Proietti, T (2002b). Some Reflections on Trend Cycle Decompositions with Correlated Disturbances, EUI Working Paper.

Scott, A and S Weber (2011). Potential Output Estimates and Structural Policy. International Monetary Fund. Kingdom of the Netherlands: Selected Issues and Analytical Notes, IMF Country Report No.11/212 11/143.

Solow, RM (1956). A contribution to the theory of economic growth. The Quaterly Journal of Economics, 70(1), 85-94. 